\title{
Childhood Psychological Abuse and Mental Health of Youth
}

\author{
Deepa K Damodaran*, Jeny Rapheal**, Varghese Paul.K***
}

\begin{abstract}
:
Mental health is clearly an integral part of health. It is part of an individual's capacity to lead a happy and fulfilling life. As a form of child maltreatment psychological abuse can have a significant impact upon the mental health. The current study examined the influencing role of psychological abuse on mental health among 211 Keralite undergraduate youth between 18 to 24 years from data collected using Mental Health Inventory and Childhood Experiences of Care and Abuse Questionnaire-2. Results revealed average mental health of youth with no significant gender difference in mental health and in the prevalence of psychological abuse except in its severity from father. Psychological abuse significantly correlated with mental health variables. A 2 way ANOVA showed significant main effect of severe maternal psychological abuse on mental health. Severity of parental psychological abuse significantly predicted poor mental health (18.7\% variability). The findings indicate the need for more effective measures to prevent psychological abuse of children.
\end{abstract}

Keywords: Child maltreatment, Mental health, Psychological abuse, Youth.

\section{INTRODUCTION}

Childhood experiences during the early years set a critical foundation for the entire life. The quality of early childhood experiences depends on steps taken by the family, community, and society in providing children with 'nurturing' environments. Thus optimal child well-being becomes possible with the exposure of children to safe, nurturing, and stable environments as it supports the development of their cognitive, emotional and social skills which help them to become healthy, productive adults. Exposure to adversities in childhood jeopardizes the normal growth and development of the individual (Boynton-Jarrett, 2008). In order to understand the origins of adult disorder, we need to understand early life experiences. Research must incorporate childhood relationships as an indicator of early attachment problems, trauma or adversity also.

*Research Scholar, Department of Psychology, Bharathiar University, Coimbatore, Tamilnadu. India

**Research Scholar, Department of Psychology, Bharathiar University, Coimbatore, Tamilnadu. India

***Head, Department of Psychology, Prajyoti Niketan College, Pudukad, Thrissur, Kerala, India

(C) 2014, D Damodaram, J Rapheal, V Paul; licensee IJIP. This is an Open Access Research distributed under the terms of the Creative Commons Attribution License (http://creativecommons.org/licenses/by/2.0), which permits unrestricted use, distribution, and reproduction in any Medium, provided the original work is properly cited. 


\section{Childhood Psychological Abuse and Mental Health of Youth}

Adverse Childhood Experiences (ACEs) are stressful or traumatic experiences in childhood including abuse, neglect, and a range of household dysfunction with a serious impact on the health, well-being and development of children throughout their lives (Anda, Croft \& Felitti, 1999; Anda, 2009). Child maltreatment is the most common and significant component of ACEs that has become a huge global problem, a human rights violation and a complex public health issue today, with a serious impact. Psychological or emotional abuse is a significant type of child maltreatment. World Health Organization defines psychological or emotional abuse as failure of a caregiver to provide an appropriate and supportive environment, and includes acts that have an adverse effect on the emotional health and development of a child (Krug, Mercy, Dahlberg, \& Zwi, 2002).

\section{PSYCHOLOGICAL ABUSE}

Psychological abuse is the most pervasive and damaging type of abuse (McGee \& Wolfe, 1991; Hart, Binggeli, \& Brassard, 1997) that has specific long lasting impact (Nicholas \& Bieber, 1996; Mullen, Martin, Anderson, Romans, \& Herbison, 1996). It is the most underreported form of maltreatment and often not recognized when other forms of maltreatment coexist (Trickett, Mennen, Kim, \& Sang, 2009). According to Attachment theory, childhood emotional abuse by caregivers leads to development of insecure attachment in the individual which in turn leads to formation of maladaptive schemas (Taussig \& Culhane, 2010).

Considerable amount of data is available today to confirm that the phenomenon of child maltreatment is prevalent in India (Asian Centre for Human Rights, 2013; Anand, 2005). UNICEF (2009) reported high prevalence of child maltreatment in the Asia-Pacific region including India in one of its multi-country study. Yelling and screaming at the child (70\%) and calling the child abusive names (29\%) are common practices of Indian parents (Krug et al., 2002). Abrahams \& Casey (2007) found "moderate" abuse (61.8\%) or abuse in "severe" and "very severe" categories (36.6\%) experienced by majority of children in the study held in Rajasthan, India. Verbal and psychological abuse was highly prevalent among them. Keralite youth also experience such maltreatment as it was revealed through several research studies. In one of such studies, a cross-sectional, population-based survey among 1668 mothers, aged 18-49, covering rural, urban and coastal areas, Nair, Ramohanan, Remadevi, Nair, Ghosh \& Leena (2009) reported use of severe verbal discipline (62\%) and severe physical abuse (50\%). Normative and abusive practices are highly prevalent in the Kerala community with mothers playing a significant role in disciplining the child.

\section{MENTAL HEALTH}

The concept of mental health has been studied extensively in the past. Gains in mental health predicts declines in mental illness and losses in mental health predicts increases in mental illness (Keyes, Dhingra \& Simoes, 2010).Compared to Western countries, the prevalence of mental disorders among adolescents and youth is low in India (Srinath, Girimaji, Gururaj, Seshadri, Subbakrishna, Bhola \& Kumar, 2005). A Kerala inquiry (Rajan, Mohamed, Kumar \& Mohammed, 2002) identified gender-related issues in mental health, human well being and stress experience among all members of age group of 15-59 years in addition to responsive persons 
between 60-69 years in a randomly selected sample of 1000 households. Men had relatively better sense of well being and better mental health than women.

Issues in mental health and behavior manifest in children during their adolescence. Mumthas and Muhsina (2014) reports prevalence of behavioural (27\%) and emotional problems (32\%) among adolescents in Kerala with psycho-social problems being very common among them. Further they report suicidal feelings (4\%), feelings that they are not respecting others (9\%) etc. More than one third of the sample were talkative, unorganized, hyperactive and introverts $(33 \%)$.

\section{PSYCHOLOGICAL ABUSE AND MENTAL HEALTH}

Children's growth and development is very much influenced by the family environment, particularly the parenting style (Taylor, Manganello \& Lee, Rice, 2010). Psychological maltreatment received during the first 3 years has profound impact on the individual as it is the period of rapid growth and development. Children with impairment in security of attachment develop problems (Sroufe, 2005) in later life including insecure attachment in adulthood (Riggs \& Kaminski, 2010). Peer relations, care giving and caretaking, intimacy, conflict resolution, sexual functioning and relational aggression are some of the aspects affected. Their beliefs about themselves and about themselves in relation to other people affect their cognitive schemas and, thereby, influencing their psychological adjustment (Wright, Crawford \& Del Castillo, 2009). Without intervention, the cycle of psychological abuse is often repeated in the next generation (Riggs \& Kaminski, 2010). The negative effects of severe emotional and sensory deprivation on later IQ, executive function and memory, psychological processing, attachment and psychiatric disorders is also revealed (Zeanah, Egger, \& Smyke, 2009).

\section{MATERIALS AND METHODS}

This non-experimental, quantitative research is an exploratory survey conducted in selected Arts and Science Colleges of Kottayam district in Kerala, South India during April-May 2013. A total of 224 undergraduate students randomly selected using a sampling frame, from a total of 600 students at the institutions constituted the sample. One student was excluded from the study as he reported to have dangerous physical illness and 12 were excluded as the data were incomplete. Thus the final sample consisted of 211 students. The tools used after testing reliability took around 20 minutes to complete and it measured (1) Demographic characteristics, (2) Mental Health and (3) Psychological abuse. Formal administrative permission from authorities, ethical clearance from Ethics committee of Jubilee Mission Medical College Hospital and Research Institute, Thrissur and informed written consent from subjects were obtained before carrying out the study. After screening, students were informed about the aims and objectives of the study. In order to safeguard autonomy and identity youth were assigned IDs, excluding own names. Participation was voluntary.

\section{Instruments}

1. Mental Health Inventory (MHI) (Veit, \& Ware, 1983): The Mental Health Inventory has been standardized in 1983 and it has 38 items. It is designed to measure psychological health and mental health status of an individual within the past month. The MHI consists of six subscales (Anxiety, Depression, Loss of behavioural /emotional control, General positive affect, Emotional 
ties and Life satisfaction), two global scales (Psychological Distress and Psychological Wellbeing), and Global Mental Health Index score. Internal consistency of various aspects of the scale ranges from .81 to .96 and authors also reported moderate test-retest reliability (.56 to .64). This study utilized the global scales and the Mental health Index Scale.

2. Childhood Experiences of Care and Abuse Questionnaire-2 (Bifulco, 2005)- Psychological abuse scale: It is a questionnaire version of the Childhood Experience of Care and Abuse interview (Bifulco, Brown \& Harris, 1994) with acceptable sensitivity and specificity (Bifulco, Bernazzani, Morgan \& Jacobs, 2005). It consists of sections on parental loss, parental care (neglect and antipathy), support in childhood, and, physical, psychological and sexual abuse before age 17 in adolescents or adults. A Likert scale on psychological abuse consisting of 17 items separately measures psychological abuse from both mother and father figures was used for the current study.

Statistical analysis was done with SPSS 20 for Windows using descriptive statistics, Correlation, independent sample t test, Chi square test, 2 way ANOVA and Multiple Regression.

\section{RESULTS}

The sample $(\mathrm{N}=211)$ for the current study consisted 75 females $(35.5 \%)$ and 136 males $(64.5 \%)$ with a mean age $( \pm \mathrm{SD})$ of $18.76 \pm 1.62$ years. All were undergraduate students and $71.6 \%$ lived in rural area with their parents $(84.4 \%)$. Most of their parents had completed higher secondary schooling (Mother-53.60\%, Father-48.30\%). Majority of fathers $(60.20 \%)$ were self employed and mothers (71.10\%) were home makers. More than half of the sample $(54 \%)$ had a monthly income between 5000 and 10000 Rs. Majority of youth had been brought up by their biological parents (Father- 96.2\%; Mother- 97.2\%). Between an average age (mean) of 2 (Father) and 5 (Mother) years, youth began to experience psychological abuse from parents.

Analysis showed that the mean Global Mental health Index score of the sample was $156.73 \pm 21.536( \pm \mathrm{SD})$ which indicated average level of Mental health. On analysis no statistically significant association was found between mental health variables such as Psychological distress, Psychological well-being, Global Mental health Index score and demographic factors such as gender, place of residence, parents' education and occupation, monthly income of the family and religion (Table not shown).

Table 1. Comparison between Mean Mental Health Scores of Males and Females

\begin{tabular}{|c|c|c|c|c|c|c|c|}
\hline \multirow[b]{3}{*}{ Mental Health } & & & & & \multicolumn{3}{|c|}{$\mathrm{n}=211$} \\
\hline & \multicolumn{2}{|c|}{ Male } & \multicolumn{2}{|c|}{ Female } & \multirow[t]{2}{*}{$\mathrm{t}$} & \multirow[t]{2}{*}{ df } & \multirow[t]{2}{*}{$\mathrm{p}^{*}$} \\
\hline & $\mathrm{M}$ & SD & $\mathrm{M}$ & SD & & & \\
\hline Psychological Distress & 60.26 & 16.23 & 63.12 & 14.07 & -1.281 & 209 & .202 \\
\hline $\begin{array}{l}\text { Psychological Well- } \\
\text { being }\end{array}$ & 55.01 & 9.93 & 52.72 & 9.28 & 1.643 & 209 & .102 \\
\hline Mental Health Index & 158.61 & 22.63 & 153.23 & 19.05 & 1.766 & 209 & .079 \\
\hline
\end{tabular}

$* p<.05$ level 
As shown in Table 1. The t test for comparison of mean scores of Psychological distress $\left(t_{(209)}=-1.28, p=.202\right)$ and Psychological well-being $\left(t_{(209)}=1.643, p=.102\right)$ dimensions of mental health among males and females showed no significant differences. Similarly, no significant difference was observed in Mental Health Index $\left(t_{(209)}=1.766, p=.079\right)$ also.

Table 2. Association between Psychological abuse and Gender

\begin{tabular}{|c|c|c|c|c|c|c|c|c|}
\hline \multirow{2}{*}{ Psychological abuse } & \multicolumn{2}{|c|}{ Male } & \multicolumn{2}{|c|}{ Female } & \multicolumn{2}{|c|}{ Total } & \multirow{2}{*}{$\chi^{2}$} & \multirow{2}{*}{$\mathrm{p}^{*}$} \\
\hline & $\mathrm{N}$ & $\%$ & $\mathrm{~N}$ & $\%$ & $\mathrm{~N}$ & $\%$ & & \\
\hline No psychological abuse & 38 & 18.01 & 20 & 9.48 & 58 & 27.49 & \multirow[b]{2}{*}{.039} & \multirow[b]{2}{*}{0.843} \\
\hline $\begin{array}{l}\text { group } \\
\text { Psychological abuse group }\end{array}$ & 98 & 72.1 & 55 & 73.3 & 153 & 72.5 & & \\
\hline
\end{tabular}

$* \mathrm{p}<0.05$ level

Table 2. shows that about $75 \%$ of the sample had experienced psychological abuse at least once either from mother/mother figure or father/father figure during the first 17 years of life. Chi square test shows that there is no significant gender difference $\left(\chi_{(1)}^{2}=.039, p>0.05\right.$ level) in the prevalence of psychological abuse among youth.

Table 3. Correlation between Psychological abuse and Mental health

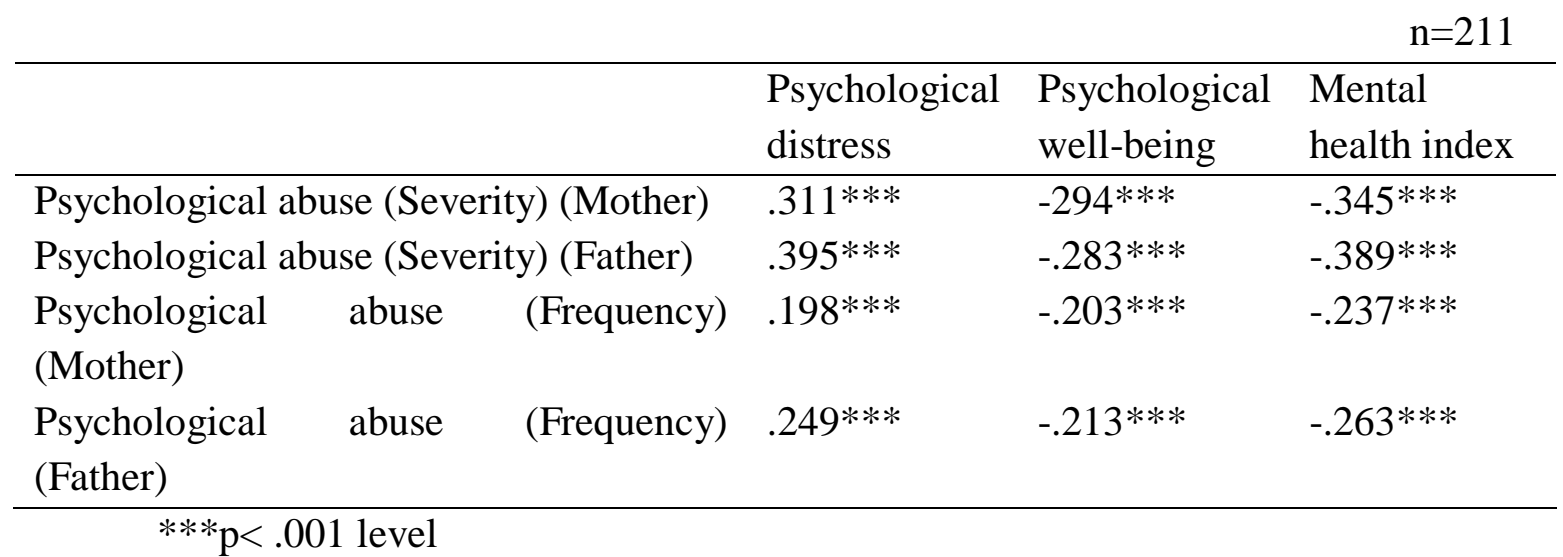

Table 3. indicates that mental health of the sample is significantly related to psychological abuse. Psychological distress is positively correlated with severity and frequency of psychological abuse from mother and father. Whereas Psychological well being and Mental health index are significantly negatively correlated with severity and frequency of psychological abuse from mother and father.

A two-way ANOVA was carried out to evaluate the influence of psychological abuse on mental health. 
Table 4. Summary of $2 \times 2$ ANOVA of Mental health by Psychological abuse

\begin{tabular}{lccccc}
\hline & Mean & SD & df & F & p \\
\hline Psychological abuse (Severity) (Mother) & & & & & \\
$\quad$ High & 140.19 & 17.994 & 2,86 & 4.877 & $.01^{* *}$ \\
$\quad$ Low & 159.92 & 17.394 & 2,86 & & \\
Psychological abuse (Severity) (Father) & & & & & \\
$\quad$ High & 157.71 & 17.92 & 2,86 & 1.339 & .268 \\
$\quad$ Low & 140.69 & 20278 & 2,86 & & \\
Psychological abuse (Severity) & & & 4,86 & 1.785 & .139 \\
(Mother)* Psychological abuse & & & & & \\
(Severity) (Father) & & & & & \\
\hline$\quad * * p<0.01$ level & & & & &
\end{tabular}

As shown in the Table 4. There is significant difference in the means of Mental Health Index of youth belonging to high and low groups of psychological abuse of mother, $\mathrm{F}(2,86)=$ $4.877, \mathrm{p}=.01$. But neither there was main effect for psychological abuse of father nor there was an interaction effect despite the tendency of the scores of youth in the severe psychological abuse group (mother) $(140.19 \pm 17.994)$ to be much lower than that of mild psychological abuse group (mother) (159.92 \pm 17.394$)$ and severe psychological abuse group (father) (157.71 \pm 17.92$)$. Although only the main effect for psychological abuse (mother) was significant, there is a reason to think that a possible interaction effect exists since low mean mental health index scores are associated with having had psychological abuse of severe nature from mother and having psychological abuse of mild severity from father. In contrast, youth with mild psychological abuse from mother and severe psychological abuse from father were affected only to a much smaller extent by having above average mental health.'

Table 5. Multiple Linear Regression Analyses predicting Mental Health from Psychological Abuse

\begin{tabular}{|c|c|c|c|c|}
\hline \multirow[b]{2}{*}{ Predictors } & \multicolumn{2}{|c|}{ Model 1} & \multicolumn{2}{|c|}{ Model 2} \\
\hline & $\mathrm{F}$ & $\beta$ & $\mathrm{F}$ & $\beta$ \\
\hline $\begin{array}{lll}\text { Psychological } & \text { abuse } & \text { (Severity) } \\
\text { (Mother) } & & \end{array}$ & $25.212 * * *$ & $-.227 * * *$ & $14.035 * * *$ & $-.352 * *$ \\
\hline Psychological abuse (Severity) (Father) & & $-.300 * * *$ & & $-.433 * * *$ \\
\hline $\begin{array}{l}\text { Psychological abuse (Frequency) } \\
\text { (Mother) }\end{array}$ & & & & .155 \\
\hline $\begin{array}{l}\text { Psychological abuse (Frequency) } \\
\text { (Father) }\end{array}$ & & & & .150 \\
\hline Adjusted $\mathrm{R}^{2}$ & .187 & & .199 & \\
\hline F Change & $25.212 * * *$ & & $2.495 * * *$ & \\
\hline
\end{tabular}

The regression analyses (Table. 5) taking psychological abuse (severity and frequency) from both parents were statistically significant models (Model 1- $F(2,208)=254.212, p<.001$; Model $2-F(4,206)=14.035, p<.001)$, indicating that both severity and frequency of 


\section{Childhood Psychological Abuse and Mental Health of Youth}

psychological abuse (inclusion in the model) from parents are good predictors of mental health index. Model 1 accounted for $18.7 \%$ of the variability and the model 2 accounted for $19.9 \%$ of the variability as indexed by the adjusted $\mathrm{R}^{2}$ statistic. Psychological abuse (Severity) (Father) as indexed by its $\beta$ value of -.30 (model 1) and -.433 (model 2), was shown to have the strongest relationship to mental health index. Frequency of psychological abuse from both parents did not predict mental health index significantly though inclusion of these variables improved the strength of the model slightly.

\section{DISCUSSION}

On the whole, mental health of Keralite youth is found to be average and no gender differences were observed whereas literature provide findings that females having lesser mental health compared to males (Rajan et.al., 2002; Mumthas \& Muhsina, 2014). About 75\% of the sample had experienced psychological abuse at least once either from mother/mother figure or father/father figure during the first 17 years of life. But there was no significant gender difference observed in the prevalence of it though severe psychological abuse from father/father figure was more prevalent among male youth. This finding has both supportive and contradictory evidences from the literature. Intra-familial childhood emotional or psychological violence is reported more amongst females whereas prevalence of extra familial emotional violence seems to be equally high in both males and females (Cawson, Wattam, Brooker, \& Kelly, 2000).

Mental health was significantly correlated with psychological abuse. Youth who had experienced psychological abuse demonstrated lesser mental health compared to those who have not experienced psychological abuse in childhood. While psychological distress was elevated in abused group, psychological well-being showed reduction with increasing severity and frequency of psychological abuse. Overall mental health also decreased as the severity and frequency of psychological abuse increased. Thus it is clear that psychological abuse reduces youth's mental health by increasing psychological distress and reducing psychological wellbeing. A two-way ANOVA too reiterates this with the evidence for significant differences in mental health index based on the severity of psychological abuse from mother. There is a possibility of psychological abuse from one parental figure particularly of mother making significant differences in mental health in the presence of psychological abuse from father as shown in this study. Low mental health index was associated with having had psychological abuse of severe nature from mother and having psychological abuse of mild severity from father although it was not statistically significant.

Psychological abuse from parents predicted poor mental health in this study. Although frequency of abuse alone did not predict significant variations, it is found to be a significant factor in the context of severe psychological abuse. While severity of abuse from both parents accounted for $18.7 \%$ variability, along with frequency of abuse, it contributed only $19.9 \%$ variability in mental health. Thus severity emerges as the key aspect of psychological abuse to be concerned about. Again, among parental figures, severity of psychological abuse from father predicts more negative changes in metal health which becomes a matter of concern in the context 
of current social changes. A growing body of literature supports the negative impact of childhood maltreatment on mental health across the life span. Keyes, Eaton, Krueger, McLaughlin, Wall, Grant, and Hasin (2012) observed that childhood maltreatment results in common psychiatric disorders and this association operates through latent liabilities to experience internalizing and externalizing psychopathology. Specific types of maltreatment exhibit specific patterns of association with internalizing or externalizing dimensions. Increased aggression and attempted suicide, social problems, delinquencies are reported from psychological unavailability and neglect in early childhood among adolescents by Iwaniec, Larkin, and Higgins (2006). Most psychologically abused adolescents in their sample had at least 1 diagnosis of mental illness. Early interactions with parents facilitate development of internal working models of self and self-in-relation to others that influence later cognitive schemas and psychological adjustment. Exposure to childhood abuse and neglect may negatively affect attachment relationships. Emotional abuse and neglect also influence later symptoms of anxiety and depression. Negative schemas of shame and vulnerability to harm are related to emotional neglect (Wright et.al, 2009).

All types of abuse involve emotional abuse and this makes emotional abuse a complex issue. Considering the significance of mental health, the above findings hold significant implications although this study consisted of youth from general population only. Emotional abuse in childhood is a significant risk factor in hindering healthy early child development and parent-child bonding and attachment because it is pervasive and persistent. Parental education on child rearing practices, training of health professionals in prevention and management of adverse impact of emotional abuse of children, and, policy making with regard to increasing awareness in prevention of it are very essential.

\section{CONCLUSION}

Improving one's psychological health is always rewarding as it benefits all aspects of one's life. Childhood psychological abuse may create negative views of self and others and it may result in maladaptive coping, ineffective social functioning and poor mental health. Being one of the serious issues related to child health, psychological abuse of children must require adequate attention from families, health professionals and policy makers for its effective prevention and management of emotionally abused.

\section{REFERENCES}

1. Abrahams, N., \& Casey, K. (2007). Teachers, knowledge, attitudes and beliefs about child abuse. Child abuse and neglect, 16(2), 221-231.

2. Anand. (2005). Survey finds child abuse rampant in State. The Hindu, Sunday, Dec 11, 2005. http://www.hindu.com/2005/12/11/stories/2005121113600400.htm.

3. Anda, R. F., Croft, J. B., Felitti, V. J., et al (1999). Adverse childhood experiences and smoking during adolescence and adulthood. Journal of American Medical Association. 282, $1652-1658$. 
4. Anda, R.. (2009). The health and social impact of growing up with adverse childhood experiences: The human and economic costs of the status quo. Retrieved from http://www.guesthouseinstitute.org/GHI\%20EJ/Archive\%209.8/1st\%20feature-Anda).pdf

5. Asian Centre for Human Rights Press Release. (2013, April). Retrieved from http://www.achrweb.org/press/2013/IND13-2013.html.

6. Bifulco, A., Bernazzani, O., Moran, P. M. \& Jacobs, C. (2005). Childhood Experience of Care and Abuse Questionnaire (CECA.Q) Validation in a community series. British Journal of Clinical Psychology, 44, 563-581.

7. Bifulco, A., Brown, G. W., \& Harris, T. O. (1994). Childhood experience of care and abuse (CECA): A retrospective interview measure. Journal of Child Psychology and Psychiatry, $35,1419-1435$.

8. Boynton-Jarrett, R., Ryan, L.M., Berkman, L.F., \& Wright, R.J. (2008). Cumulative violence exposure and self-rated health: Longitudinal study of adolescents in the United States. Pediatrics, 122 (5), 961-970.

9. Cawson, P., Wattam, C., Brooker, S., \& Kelly, G., (2000) Child Maltreatment in the United Kingdom: A Study of the Prevalence of Child Abuse and Neglect. London: NSPCC.

10. Hart, S., Binggeli, N., \& Brassard, M. (1997). Evidence for the effects of psychological maltreatment. Journal of Emotional Abuse, 1(1), 27-58.

11. Iwaniec, D., Larkin, E., \& Higgins, S. (2006). Research review:risks and resilience in cases of emotional abuse. Child, Family, Social Work. 11, 73-82.

12. Keyes, C. L. M., Dhingra, S. S., \& and Simoes, E. J. (2010). Changes in level of positive mental health as a predictor of future risk of mental illness. American Journal of Public Health. 100 (12).2366-2371.doi:10.2105/AJPH.2010.192245.

13. Keyes, M. K., Eaton, R. N., Krueger, F. R., McLaughlin, K.A., Wall, M. M., Grant B. F., \& Hasin, D. S. (2012). Childhood maltreatment and the structure of common psychiatric disorders. The British Journal of Psychiatry, 200, 107-115. doi: 10. 1192/bjp.bp.111.093062.

14. Krug, E. G., Mercy, J. A., Dahlberg, L. L., \& Zwi, A. B. (2002). The world report on violence and health. Lancet, 360, 1083-1088.

15. McGee, R.. A., \& Wolfe, D. A. (1991). Psychological maltreatment: Toward an operational definition. Development and Psychopathology, 2, 425-444.

16. Mullen, P. E., Martin, J. L., Anderson, J. C., Romans, S. E., \& Herbison, G. P. (1996). The long-term impact of the physical, emotional, and sexual abuse of children:A community study. Child Abuse \& Neglect, 20, 7-21.

17. Mumthas, N. S \& Muhsina, M. (2014). Psycho-Social Problems of Adolescents at Higher Secondary Level. Guru Journal of Behavioral and Social Sciences. 2 (1), 252-257.

18. Nair, M. K., Rajmohanan, K., Remadevi, S., Nair, S. M., Ghosh, C. S., \& Leena, M. L. (2009). Child disciplining practices in Kerala [Supplement]. Indian Pediatrics, an:46, 83-85.

19. Nicholas, K. B., \& Bieber, S. L. (1996). Parental abusive versus supportive behaviors and their relation to hostility and aggression in young adults. Child Abuse \&Neglect, 20, 1195-1211. 
20. Rajan, S.I., Mohamed, E., Kumar, K. A., \& Mohammed, P.M. S. (2002). 'Gender and Mental Health in Kerala', (Kerala Mental Health Survey), Report submitted under the MIMAP Gender Network Project (Phase II).

21. Riggs, S., \& Kaminski, P. (2010). Childhood emotional abuse, adult attachment, and depression as predictors of relational adjustment and psychological aggression. Journal of Aggression, Maltreatment and Trauma. 19 (4):75-104.

22. Srinath, S., Girimaji, S. C., Gururaj, G., Seshadri, S., Subbakrishna, D. K., Bhola, P., \& Kumar, N. (2005). Epidemiological study of child \& adolescent psychiatric disorders in urban \& rural areas of Bangalore, India. Indian Journal of Medical Research, 122, 67-79.

23. Sroufe, L. A. (2005). Attachment and development: a prospective, longitudinal study from birth to adulthood. Attachmet and Human Development. 7 (4), 349-367.

24. Taussig, H. N., \& Culhane, S. E. (2010). Emotional maltreatment and psychosocial functioning in preadolescent youth placed in out-of-home care. Journal of Aggression, Maltreatment and Trauma, 19(1), 52-74.

25. Taylor, C. A., Manganello, J. A., Lee. S. J., \& Rice, J. C. (2010). Mother's spanking of 3 year old children and subsequent risk of children's aggressive behaviour. Pediatrics. 125 (5). Available at : www.pediatrics.org/cgi/content/full/125/5/e1057.

26. Trickett, P. K., Mennen, F. E., Kim, K., \& Sang, J. (2009). Emotional abuse in a sample of multiply maltreated, urban young adolescents:issues of definition and identification. Child Abuse and Neglect. 33 (1), 27-35.

27. UNICEF. (2009). South Asia in Action: Preventing and responding to child trafficking: Analysis of anti-trafficking initiatives in the region. Florence: UNICEF Innocenti Research Centre.

28. Veit, C.T., \& Ware, J.E. Jr. (1983). The structure of psychological distress and well-being in general populations. Journal of Consulting Clinical Psychology, 51, 730-742.

29. Wright, M. O., Crawford, E., \& Del Castillo, D. (2009). Childhood emotional maltreatment and later psychological distress among college students: the mediating role of maladaptive schemas. Child Abuse and Neglect, 33 (1), 59-68.

30. Zeanah, C. H., Egger, H. L., Smyke, A. T, et al. (2009). Institutional rearing and psychiatric disorders in Romanian preschool children. American Journal of Psychiatry, 166 (7), 777-785. 


\section{APPENDIX}

Table A1.

Correlation between Psychological abuse and Mental health variables

$$
\mathrm{n}=211
$$

\begin{tabular}{|c|c|c|c|c|c|}
\hline & $\begin{array}{l}\text { Psychological } \\
\text { distress }\end{array}$ & $\begin{array}{l}\text { Psychological } \\
\text { well-being }\end{array}$ & $\begin{array}{l}\text { Mental } \\
\text { health index }\end{array}$ & M & SD \\
\hline Psychological distress & - & & & 61.28 & 1.55 \\
\hline Psychological well-being & $-.551 * * *$ & - & & 54.19 & 9.75 \\
\hline Mental health index & $-.886 * * *$ & $.802 * * *$ & - & 156.73 & 21.54 \\
\hline $\begin{array}{l}\text { Psychological abuse } \\
\text { (Severity) (Mother) }\end{array}$ & $.311 * * *$ & $-294 * * *$ & $-.345 * * *$ & 2.95 & 3.85 \\
\hline $\begin{array}{l}\text { Psychological abuse } \\
\text { (Severity) (Father) }\end{array}$ & $.395 * * *$ & $-.283 * * *$ & $-.389 * * *$ & 2.35 & 3.35 \\
\hline $\begin{array}{l}\text { Psychological abuse } \\
\text { (Frequency) (Mother) }\end{array}$ & $.198 * * *$ & $-.203 * * *$ & $-.237 * * *$ & 3.92 & 4.88 \\
\hline $\begin{array}{l}\text { Psychological abuse } \\
\text { (Frequency) (Father) }\end{array}$ & $.249 * * *$ & $-.213 * * *$ & $-.263 * * *$ & 3.26 & 6.00 \\
\hline
\end{tabular}

